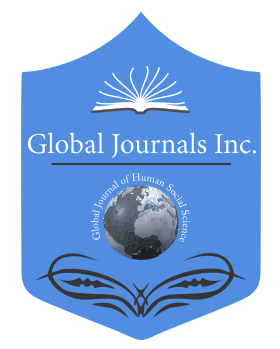

\title{
The use of E-Cigarettes among Adolescents in the United States
}

\author{
By Dr. Henry O’lawrence, Dr. Linda Martinez, Andre Garcia, Patricia Ramos,
} Dejay Pequillo \& Carina Marquez

California State University

Abstract- Latest research has indicated that e-cigarettes are not safe for all ages, from kids to young adults, and it has been estimated that $99 \%$ of the e-cigarettes sold in the U.S. contained nicotine. This study further investigated why the underage smoking of e-cigarettes is increasing, especially among youth in California. Additionally, the study investigated secondary data from California's Health Interview Survey (CHIS, 2017) was used to determine if the health effects caused by e-cigarette smoking, as well as future directions and implications. The research question was to determine whether smoking has increased in teens in the United States due to vaping and e-cigarette devices and whether there is a positive correlation to e-cigarette advertisement and the insufficiency of government regulations The researchers came up with a single hypothesis determine if the lack of information about the negative health effects, regulation, and parental guidance are contributing factors to the increase of adolescent smoking in the United States.

Keywords: e-cigarettes, vaping, adolescent, teens, youth, advertisement, regulation, health effects.

GJHSS-A Classification: FOR Code: 220499

Strictly as per the compliance and regulations of:

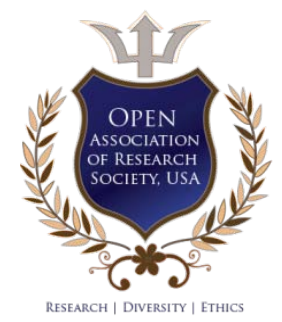

(C) 2020. Dr. Henry O'lawrence, Dr. Linda Martinez, Andre Garcia, Patricia Ramos, Dejay Pequillo \& Carina Marquez. This is a research/review paper, distributed under the terms of the Creative Commons Attribution-Noncommercial 3.0 Unported License http://creativecommons.org/licenses/by-nc/3.0/), permitting all non-commercial use, distribution, and reproduction in any medium, provided the original work is properly cited. 


\title{
The use of E-Cigarettes among Adolescents in the United States
}

\author{
Dr. Henry O'lawrence ${ }^{\alpha}$, Dr. Linda Martinez ${ }^{\circ}$, Andre Garcia $^{\circ}$, Patricia Ramos ${ }^{\omega}$, Dejay Pequillo \\ \& Carina Marquez
}

Abstract- Latest research has indicated that e-cigarettes are not safe for all ages, from kids to young adults, and it has been estimated that $99 \%$ of the e-cigarettes sold in the U.S. contained nicotine. This study further investigated why the underage smoking of e-cigarettes is increasing, especially among youth in California. Additionally, the study investigated secondary data from California's Health Interview Survey (CHIS, 2017) was used to determine if the health effects caused by e-cigarette smoking, as well as future directions and implications. The research question was to determine whether smoking has increased in teens in the United States due to vaping and e-cigarette devices and whether there is a positive correlation to e-cigarette advertisement and the insufficiency of government regulations The researchers came up with a single hypothesis determine if the lack of information about the negative health effects, regulation, and parental guidance are contributing factors to the increase of adolescent smoking in the United States.

Keywords: e-cigarettes, vaping, adolescent, teens, youth, advertisement, regulation, health effects.

\section{InTRODUCTION}

S cientists are still trying to determine the long-term effects of e-cigarettes, as a result of some of the ingredients in the e-cigarette's aerosols considered to be possibly harmful to the lungs in the long-term. It is disturbing to find that both children and adults smoking e-cigarette are actually been poisoned by swallowing, breathing, or ab sorbing e-cigarette liquid through their skin or eyes. It is alarming to discover that, approximately $50 \%$ of calls to poison control centers for e-cigarettes are for kids 5 years old or younger nationally (CDC, 2020). Since 2007, when e-cigarettes first entered the U.S. marketplace, it is estimated that since 2014, vaping has been the most commonly used tobacco products among U.S. youth. Among the middle and high school students, the rate of usage increased approximately 900\% between 2011-2015, before declining slightly for the first time during the 2015-2017 (Office of the Surgeon General, 2016; \& Wang, et al., 2017). As of 2018, current e-cigarette usage increased $78 \%$ among high school students during the past year, from $11.7 \%$ in 2017 to $20.8 \%$ in 2018 and more than 3.6 million U.S. youth, including 1 in 5 high school students and 1 in 20 middle school students, currently use ecigarettes (Cullen, et al., 2018).

Author o: California State University, Long Beach. e-mail: linda.martinez@csulb.edu
The increase of this new trend is attributed to advertisement and the promise of a healthier alternative. Even though these advertisements were intended to influence smokers in the adult demographic, the youth have actually been affected the most due to the popularity and peer influences. The regulatory body of the FDA to cover e-cigarettes was created at the Federal level in 2016. The newly created Family Smoking Prevention and Tobacco Control Act (FSPTCA) with FDA has the authority to develop regulations that address the manufacturing, marketing and sale of e-cigarettes. However, the FSPTCA does not prevent states and communities from adopting many strategies related to e-cigarettes. Additionally, there are also many strategies that FDA does not have the authority to implement and that states can implement, including the usage of ecigarettes in smoke-free policies, pricing strategies, and increasing the age of sale for tobacco products to 21 (CDC, 2020). In 2017, approximately 2.1 million teens were using electronic cigarettes and in 2018, more than 3.6 million U.S. middle school students (4.9\%) and high school students (20.8\%) had used e-cigarettes in the past 30 days, when asked if they have used it recently (CDC, n.d.). However, the penalties of selling to minorities vary from state to state with no federal law governing retailer practices in this area. In the state of California, the local law enforcement agencies have the authority under California Penal Code Section 830.1. to enforce this law and violators are subject to a fine up to $\$ 200$ for the first violation and; $\$ 500$ for $2^{\text {nd }}$ violation; and $\$ 1000$ for $3^{\text {rd }}$ or sub sequent violation.

Ever since electronic cigarettes appeared in the market, people believed that this was a healthier alternative to smoking a cigarette because it did not have all that harmful chemicals that a cigarette contains. There was limited data or research back to support that claim and the public believed it because they were told by friends and others that smoking electronic cigarettes was a healthier option. A research study conducted by the FDA (2019) in 2019 indicated a sharp increase of usage due to the high nicotine content; appealing flavors; and the ability to be easily concealed and used discreetly. Due to the popularity of this product, teenagers began to use e-cigarettes because of the different flavors and the overall acceptability of the product. This then led to a growing population of children smoking electronic cigarettes. Due to this 
increase, people started to become concerned for individuals who are smoking electronic cigarettes, such as their friends, relatives, and even their children.

\section{il. Statement of Problem}

Recently, e-cigarette usage has been the social trend with young Americans. Because of the increase in exposure and media, cigarette companies appear to be targeting their advertising to include young Americans. According to the Center for Disease Control and Prevention (2017), about $69 \%$ of middle and high school students were exposed to e-cigarette advertisements. These corporate promotions appeal to the masses of the young, they are encouraging a misleading impression that smoking is "cool," leading teenagers to believe that smoking is "fun" or "safe." This can lead to a widespread occurrence of peer-pressure between young Americans at a time when popularity and acceptance are thought to be of with great importance (CDC, 2017).

With the increasing epidemic of e-cigarette usage in young Americans and with lack of legal regulations, many American children are unknowingly causing permanent and significant harm to themselves. As of November 13, 2019, there have been 2,172 cases of hospitalization caused by e-cigarette and vaping products with $14 \%$ of patients under the age of 18 (CDC, 2019a). Due to the promotion of false and misleading information of e-cigarettes companies, adolescent health has been decreasing and leading to life threatening situations.

\section{ili. Purpose of the Study}

The use of e-cigarettes among teens has increased rapidly and has been gaining popularity over the years due to the belief that it is a healthier alternative to regular traditional cigarettes; the fact remains however, that there is nicotine contained in these products, which are highly addictive and can affect the human body. Teens are highly influenced through peers and the widespread advertising of the products, via media, for which advertising for conventional tobacco products is prohibited. Advertising, such as on TV, and the low cost as compared to conventional cigarettes has contributed to the increase in e-cigarette usage among youth (CDC, 2020). Youth nicotine exposure is at a high level, causing some serious side effects. One of these side effects is addiction to nicotine.

This type of exposure at a young age causes serious health problems for a teenager. Nicotine consumption has developmental effects on the brain's prefrontal cortex, such as cognition, attention, and mood (CDC, 2016). As teenagers, being exposed to nicotine in vaping, might cause them to smoke traditional cigarettes later on or even consume other forms of drugs that are harmful to the body. Therefore, the purpose of this study was to investigate the health risk factors and popularity of e-cigarette usage in teens in the California. It is a known fact that e-cigarettes are unsafe among young people, as many also reported that using e-cigarettes is due to curiousness of the new products and the belief that the products are less harmful than conventional cigarettes.

\section{Significance of the Study}

The use of tobacco is prevalent and a common addiction, mostly recognized in the United States. As technology has grown over the years, e-cigarettes have taken over traditional cigarette usage and infiltrated the minds of young adults. The effects of advertisements amongst adolescents suggests that the effect of warning statements and risk factors are not effective in the decrease of the urge to smoke. Some of these advertisements contain celebrity endorsements, sponsorships from sporting events, and cartoon characters that actually give it positive light and a sign of approval. These entertaining commercials increase the urge for young adults to consume and buy e-cigarette products (Sanders, Schleicher, Fortmann, \& Henriksen, 2019). New research shows that mint and menthol ecigarette use among high school users rose from 16\% in 2016 to $57.3 \%$ in 2019 (Truth Initiative, 2019).

Although traditional cigarette advertisements have been banned from the United States television, this does not include the promotion of electronic cigarettes. These advertisements are reaching approximately 24 million youths today, not including social media's involvement. These weak regulations of promotion have deemed using e-cigarettes as a positive and socially acceptable norm (Reinhold, Kenne \& Fisehbein, 2018). Other studies also indicated that exposure to Electronic Nicotine Delivery Systems (ENDS) visual imagery has not only increased the intent to smoke, but positive feelings about the product (King, Smith, Fridberg, Matthews, McNamara, Dingcai, \& Cao, 2016). It is of vital importance that advertisements openly report risk factors, as well as provide all side effects that result from these nicotine-based vap or products.

\section{Methodology}

In this study, data was retrieved from the 2017 California Health Interview Survey (CHIS). The data investigate the health risk factors and the popularity of electronic cigarettes use in teens in the United States. Observing how teens use electronic cigarettes relates to the family type of the teen, safety in the neighborhood, and parent's involvement in the teen's social and school life. The sample population of teens provided by the 2017 CHIS teen data totaled approximately 448 participants in the study. This secondary data analysis from the California Health Interview Survey (CHIS, 2017) and from additional reliable resources was used for this 
research investigating current teen smoking habits. This study is descriptive in nature and quantitative because the variables were selected from the categorical variables of a secondary data source. The results that are gathered from this study were used further to determining the effects on health from electronic cigarettes in California. Using SPSS (2017), a sample size of 448 applicants that completed the survey, were analyzed and the results showed that $8.9 \%$ of adolescents smoked electronic cigarettes.

First, cases were filtered out on the relationship between age and smoking electronic cigarettes, which is represented in Table 1 below. About 40 participants $(8.93 \%)$ indicated that they have smoked electronic cigarettes, as opposed to a total of 408 (91.07\%) who stated no. The age category that has the highest number of electronic smokers is 17-year-olds with 13 participants $(20 \%)$ who stated that they have smoked electronic cigarettes and the other 52 (80\%) who said no. The age category with the lowest percentage who did not smoke electronic cigarettes was the 12-yearolds, and out of 75 participants (100\%) said that they did not smoke electronic cigarettes.

a) Survey Design

This study investigated data provided by the California Health Interview Survey (CHIS) and used the Statistical Package for Social Science (SPSS) in its data collection. In addition, reviewed articles and statistics published from government agencies, such as the Center for Disease Control and Preventions (CDC) and the National Institute of Health $(\mathrm{NIH})$ were also used.

\section{b) Data Collection}

For this report, teen data from the CHIS 2017 survey was analyzed by using SPSS, a statistical software package used for several types of research in an array of different fields. SPSS frequencies were used to determine if the sample size conveyed association with the literature review findings. CHIS is the largest depository of health surveys of all areas of health including health issues, health behaviors, health patterns, and among other health and non-health related services.

\section{c) Independent Variables}

Teens who had smoked an electronic cigarette.

\section{d) Dependent Variables}

Dependent categories included the following variables: highlighted parent-involvement, household size, family type (4-levels), and if the adolescent felt safe in their respective neighborhood. The main goal was to determine if there was any correlation or patterns contributing to juvenile e-cigarette usage.

Table 1: Responded to the question of have you ever smoked electronic cigarettes

\begin{tabular}{cccc}
\hline Age & Yes & No & Total \\
\hline 12 & $0 \%$ & $100 \%$ & 75 \\
13 & $1.43 \%$ & $98.57 \%$ & 70 \\
14 & $5.26 \%$ & $94.74 \%$ & 76 \\
15 & $17.28 \%$ & $82.72 \%$ & 81 \\
16 & $9.88 \%$ & $90.12 \%$ & 81 \\
17 & $20 \%$ & $80 \%$ & 65 \\
Total Percentages $(N=448)$ & $8.93 \%$ & $91.07 \%$ & 448 \\
\hline
\end{tabular}

The Chi-squared value for the relationship between age and if the participant smoked electronic cigarettes is $\chi 2=30.29$ and the P-value $=0.00$. The $p$ value is less than 0.05 indicating that there is a relationship between age and smoking electronic cigarettes. Table 1 explains that as teenagers reach17years-old, they tend to smoke electronic cigarettes according to the 2017 CHIS teen data set. As this is significant in California in the year 2017, CDC reported that $11.7 \%$ of the total population of teenagers in the United States in 2017 showed that 1 in 4 high school and middle school students smoke or vape electronic cigarettes (LaVito, 2019). As the years progress, age and smoking electronic cigarettes will be greatly affected. In 2017, teenagers in California who used electronic cigarettes was only 9\% and in 2018 that percentage increased significantly to $13 \%$.

Another case that was filtered out was the parent's involvement in the teens social and school life.
Data collected from the $2017 \mathrm{CHIS}$ data set stated that 39 teens (8.88\%) who received notices about absenteeism from the schools, smoked electronic cigarettes. The other $91.12 \%$ said that they were noticed, but did not smoke electronic cigarettes. For adults being active in the teenager's life, $9.07 \%$ of the teens said that they smoked electronic cigarettes. The other $90.93 \%$ said that it was true, but did not smoke a cigarette. Lastly, for the adults believing that the teenager will be a success $8.88 \%$ of teens said that they smoked electronic cigarettes. The other $91.12 \%$ said that they did not smoke a cigarette.

The Chi-square value for the relationship between adults believing that the teenager will be a success and if the participant smoked electronic cigarettes is $\chi 2=12.38$ and the P-value $=0.015$. The $\mathrm{p}$-value is less than 0.05 indicating that there is a relationship between adults believing that the teenager will be a success and if the participant smoked 
electronic cigarettes. It appears that when the parents or adults exert pressure on a teenager, then the teenager will most likely smoke electronic cigarettes due to the stress. Although there was no significant relationship between adults noticing teens absent from school and smoking electronic cigarettes and between adults caring about the teen in school and smoking, more research needs to be conducted, but in 2018 and 2019, there is some significance as there is more evidence.

\section{e) Hypotheses Testing}

A Chi-square test was performed the using CHIS 2017 teen data to determine if there was a correlation between teens smoking an e-cigarette and whether parental, legal and social factors were contributed. From the p-values given, the level of significance proved that there was a strong correlation to these variables.

The hypothesis predicted that the lack of information about health effects, regulation, and parental guidance are contributing factors to the increase of adolescent smoking in the United States. Based off this data collection and literature review, the study concluded to accept the hypothesis as true. Additionally, CDC and literature review findings also supported the hypothesis claim.

\section{Vi. Comparative Analysis CHIS \& CDC}

Center for Disease Control and Prevention (2019) statistics details that the number of teenage ecigarettes users has grown from $11.7 \%$ in 2017 to $20.8 \%$ in 2018, while no other change was found in other tobacco products. CDC further notes that the number of users in the e-cigarette population in youth increased 1.5 million from 2017 to 2018. Compared to the sample size given using 2017 CHIS data, this study can deduce that there is a growing epidemic of e-cigarette users within the United States. The CDC stated that since the introduction and availability of electronic cigarettes to the general public, there has been an ongoing outbreak to lung and cardiovascular injuries associated with electronic cigarettes (Raven, 2019).

This new lung disease identified as EVALI (e-cigarettes or vaping associated lung disease) has caused multiple injury cases and dozens of deaths. An example of one of these cases was popcorn lungs. Popcorn lungs were first introduced to employees that worked in popcorn manufacturers because of the chemical called diacetyl that was within the ingredients to make popcorn. That issue was solved by the FDA, but came back when electronic cigarettes entered the market. The effects of popcorn lungs are caused by the diacetyl chemical, which inflames the bronchioles and alveoli in the lungs. Those who have been injured by vaping for over a period of months or years could experience a deterioration of their health and difficulty of breathing. This particular type of lung disease is severe and is irreversible. Recently, there was a case in the United States where a 17-year-old boy that had vaped for a couple months was hospitalized in intensive care for 47 days due to lung damage. Doctors even considered the possibility that they might need to do a double lung transplant (BBC, 2019). More cases are being studied by the CDC, including the possibility that can affect teenagers mentally, as well as physically.

\section{Vil. Conclusion and Recommendations}

The use of e-cigarettes among teens has skyrocketed in recent years and e-cigarettes are now the most common use tobacco products, especially among teens. Many young teens have started smoking ecigarettes between the ages of 15 to 17 years old (CDC, 2018). E-cigarettes are considered to be a healthier alternative to regular traditional cigarettes, but there are still a lot of health risks associated with them. Usage of teens who start smoking e-cigarettes at a young age can lead to issues with brain development creating negative impacts on overall health. When young teens are exposed to nicotine during young adulthood, it can change how the brain works, leading to a lifetime of addiction and in some cases, causing long-lasting mood disorders (CDC, 2018). From 2017 to 2018, the number of middle and high school students who said they had used a tobacco product within the previous 30 days rose by $38.3 \%$, according to the Centers for Disease Control and Prevention (CDC, 2018). This is a cause for concern because tobacco usage is the leading cause of preventable disease and death in the United States and because nearly all tobacco products contain nicotine, which is why teens are now at risk (CDC, 2018).

Many parents from e-cigarette using homes were not fully aware of the health and safety risks of e-cigarettes to user and the individuals around them. Parents viewed e-cigarettes as safer than regular smoking cigarettes (Garbutt et al., 2016). Parental e-cigarette usage increases their children's health risk of nicotine addiction at an early age, through role modeling and normalization. A child who is exposed to cigarette usage by the parent, especially before young adulthood, is more likely to smoke cigarettes (Garbutt et al., 2016). Some parents have reported that they use electronic cigarettes as an alternative to quit smoking regular cigarettes and wanting to reduce the exposure of second-hand smoke to their children. However, the majority of children in e-cigarette using households were also exposed to cigarettes, which is raising concern about the widespread use of e-cigarettes among parents about the safety hazards of children in their home (Garbutt et al., 2016). E-cigarettes may provide some benefits by helping to reduce parental use of regular cigarettes, but exposure to these products can lead to negative outcomes and possible addiction at an 
early age. Parents should not be using e-cigarettes in the house and in front of their children, because that is how many young teens get hooked (Garbutt et al., 2016).

The study did not look into all aspects of the environment around the adolescents' life that may influence their usage of e-cigarettes. The SPSS data also limited data collection because the surveyed population did not report usage of e-cigarettes as highly as our outside sources. Data shows that in today's world, e-cigarettes have substantially sub stituted for the use of traditional cigarettes. More variables may include socioeconomic status, race, and gender of the population, not discussed within our research. To reduce usage of e-cigarettes in the future, studies should not be limited to certain lifestyles, so the targeted population may be assisted in reducing their consumption.

This research tends to influence the targeted community with information about the negative health effects brought upon adolescents from using ecigarettes. It is vital that all the factors that influence the youth be brought to the attention of the population and that the government act in order to prevent the continuing growth of e-cigarette sales. The more research done on the harmful effects of e-cigarettes, the more likely the resulting information will further inform teenagers about the grave dangers they are exposed to from the unlawful chemicals used within those products. It is imperative that more attention be shined on the topic because as of today, advertisement of these products is not illegal like it is for traditional cigarettes. Because there has not been much information or research done on the long-term effects of e-cigarettes, it is important that research continues, as new information comes to light over the years. It has only been since 2019 that horror stories of mortalities and irreversible damages to the body have been broadcast across the globe.

\section{Vili. Future Directions}

Although there has been a recent decline in the sales of e-cigarettes and electronic tobacco usage due to recent negative headlines, the future of e-cigarettes is still on the rise $(\mathrm{Wu}, 2019)$. Many states are now trying to ban flavoring e-cigarettes, as well as regulating them further. With recent long-term health effects coming to light in 2019, regulations among the 50 states have been updated to protect the public. Some huge retail stores have also removed e-cigarettes, such as the popular brand Juul from their shelves. However, although the negative effects of e-cigarettes and flavored vapes are being slowly unraveled, the projected growth of the industry is still quickly rising. In the future, flavoring may be removed altogether to have less appeal for the younger crowd in hopes of decreasing the popularity among adolescents. Advertisement may also take a quick turn and be banned altogether, like the advertising ban on traditional cigarettes. The lack of positive advertisement may diminish the heavy influence placed upon the e-cigarettes by impressionable teenagers, leading to a steady decline in sales amongst them.

\section{Recommendations}

The increase in e-cigarette smoking in teens has become a serious issue and lately, it has been gaining a lot of popularity over social media, which is influencing many teens to become addicted on a daily basis. They need to be aware that the chemicals in electronic cigarettes have the same risks as smoking traditional cigarettes. To prevent teens from continuing to use e-cigarettes, there needs to be plans in place to educate them about the dangers of e-cigarettes, so that they will not continue to use the products and stricter tobacco policies must be adopted. Schools should be a tobacco free campus, so that they are not easily influenced by their peers. The household occupants need to be aware of the danger and prohibit tobacco use, especially for the teens in the home. Although, we continue to learn more about e-cigarettes each day, we need to increase awareness of the harmful effects of ecigarettes among adolescents, so e-cigarette usage does not continue to escalate in the future.

\section{References Références Referencias}

1. BBC. (2019, November 22). Vaping linked to teen's 'popcorn lung' type injury. Retrieved from https:// www.bbc.com/news/world-us-canada-50494871

2. Center for Disease Control (2020). Quick facts on the risks of e-cigarettes for kids, teens, and young adults. Retrieve from https://www.cdc.gov/tobacco/ basic information/e- cigarettes/Quick-Facts-on-theRisks-of-E-cigarettes-for-Kids-Teens-and-YoungAdults.html

3. Center for Disease Control and Prevention. (2019a). CDC, states update number of cases of lung injury associated with use of e-cigarette, or vaping, products. Retrieved from https://www.cdc.gov/ media/releases/2019/s1114-update-number-vaping. html

4. Center for Disease Control and Prevention. (n.d.). Ecigarette ads and youth. Retrieved from https:// www.cdc.gov/vitalsigns/ecigarette-ads/index.html\# anchor_1490283089

5. Center for Disease Control and Prevention. (2016). E-cigarette use among youth and young adults: A report of the surgeon general. Retrieved from https://www.cdc.gov/mmwr/volumes/67/wr/mm6722 a3.htmhttps://www.ncbi.nlm.nih.gov/books/NBK538 688/\#ch3.s3 
6. Centers for Disease Control and Prevention. (2018, June 8). Tobacco products use among middle and high school students-united states 2011-2017. Retrieved from https://www.cdc.gov/mmwr/ volumes/67/wr/mm6722a3.htm

7. Centers for Disease Control and Prevention. (2019b). Tobacco Use by Youth is Rising. Retrieved from https://www.cdc.gov/vitalsigns/youth-tobaccouse/index.html

8. Cullen, K. A., Ambrose, B. K., Gentzke, A. S., Apelberg, B. J., Jamal, A., \& King, B. A. (2018). Notes from the field: Increase in use of electronic cigarettes and any tobacco product among middle and high school students - United States, 20112018. MMWR Morbidity \& Mortality Weekly Report 2018, 67(45), 1276-1277.

9. Duke, J. C., Lee, Y. O., Kim, A. E., Watson, K. A., Arnold, K. Y., Nonnemaker, J. M., \& Porter, L. (2014, July 1). Exposure to electronic cigarette television advertisements among youth and young adults. Retrieved from https://pediatrics.aappublications. org/content/134/1/e29\#sec-8.

10. FDA. (2019). Results from the National Youth Tobacco Survey. Retrieved from https://www.fda. gov/tobacco-products/youth-and-tobacco/youthtobacco-use-results-national-youth-tobacco-survey.

11. FindLaw. (2019, January 1). Mississippi code title 97: Crimes 97-32-51 prohibition of the distribution of alternative nicotine products to minors. Retrieved from https://codes.findlaw.com/ms/title-97-crimes/ ms-code-sect-97-32-51.html

12. Garbutt, J. M., Miller, W., Dodd, S., Bobenhouse, N., Sterkel, R., \& Strunk, R. C. (2015, August 22). Parental Use of Electronic Cigarettes. Retrieved from https://www.ncbi.nlm.nih.gov/pmc/articles/ PMC4639418/

13. King, A., Smith, L., Fridberg, D., Matthews, A., McNamara, P., \& Dingcai C. (2018, July 4). Exposure to electronic nicotine delivery systems (ENDS) visual imagery increases smoking urge and desire. Retrieved from http://csulb.idm.oclc.org/ login?url=https://search.ebscohost.com/login.aspx ?direct $=$ true $\& \mathrm{db}=$ rzh\&AN $=113424666 \&$ site $=$ ehost -live

14. King, A. C., Smith, L. J., Fridberg, D. J., Matthews, A. K., McNamara, P. J., \& Cao, D. (2016). Exposure to electronic nicotine delivery systems (ENDS) visual imagery increases smoking urge and desire. Psychology of Addictive Behaviors, 30(1), 106-112. doi: https://doi-org.csulb.idm.oclc.org/10.1037/adb 0000123

15. La Vito, A. (2019a). CDC says teen vaping surges to more than 1 in 4 high school students. Retrieved from https://www.cnbc.com/2019/09/12/cdc-saysteen-vaping-surges-to-more-than-1-in-4-highschool-students.html
16. La Vito, A. (2019b). E-cigarette giant juul suspends sales of all fruity flavors ahead of looming US ban. Retrieved from https://www.cnbc.com/2019/10/17/ecigarette-giant-juul-suspends-sales-of-fruity-flavorsahead-of-looming-ban.html.

17. Loria, K. (2019, February 13). Use of e-cigarettes among teens is 'exploding': New numbers from the CDC show that juul and other e-cigs are extremely popular. Retrieved from https://www.consumer reports. org/electronic-cigarettes/e-cigarette-useamong-teens-is-exploding/_

18. Mantey, D. S., Barosso, C. S., Kelder, B. T., \& Kelder, S. H. (2019, May 1). Retail access to ecigarettes and frequency of e-cigarette use in high school students. Tobacco Regulatory Science, 5(1). doi: 10.18001.

19. Mordor Intelligence. (2019). E-cigarette market. Retrieved from https://www.mordorintelligence. com/industry-reports/global-e-cigarettes-marketindustry.

20. National Academic of Sciences Engineering Medicine (NAP). (2015, January 1). Public implications of raising the minimum age of legal access to tobacco products-appendix b: State lawstobacco transfers. Retrieved from https://www. nap.edu/read/18997/chapter/13

21. National Center for Chronic Disease Prevention and Health Promotion (US) Office on Smoking and Health. (2016, January 1). Patterns of e-cigarette use among U.S. youth and young adults. Retrieved from https://www.ncbi.nlm.nih.gov/books/ NBK538687/.

22. Office of Adolescent Health. (2019, May 1). Adolescents and tobacco: Trends. Retrieved from https://www.hhs.gov/ash/oah/adolescentdevelopment/substance-use/drugs/tobacco/trends/ index.html.

23. Products, C. for T. (2019, February 6). 2018 NYTS data: A startling rise in youth e-cigarette use. Retrieved from https://www.fda.g ov/tobaccoproducts/youth-and-tobacco/2018-nyts-datastartling-rise-youth-e-cigarette-use.

24. Products, C. for T. (2019). Results from the national youth tobacco survey. Retrieved from https://www. fda.gov/tobacco-products/youth-and-tobacco/youth -tobacco-use-results-national-youth-tobaccosurvey.

25. Raven, K. (2019, November 8). Teen vaping linked to more health risks. Retrieved from https://www. yalemedicine.org/stories/teen-vaping/

26. Reinhold, B., Bhamidipalli, S., Bryant, J., Kenne, D., \& Fischbein, R. (2018, January 17). Associations of attitudes towards electronic cigarettes with advertisement exposure and social determinants: A cross sectional study. Retrieved from http://csulb. idm.oclc.org/login?url=https://search.eb scohost.co 
$\mathrm{m} /$ login .aspx?direct $=$ true $\& \mathrm{db}=\mathrm{rzh} \& \mathrm{AN}=121277861$ \&site $=$ ehost-live

27. Rense, S. (2019, October 14). Seven states have banned vapes so far. Is all of America next? Retrieved from https://www.esquire.com/lifestyle/ health/a29067489/which-states-banned-flavored-ecigarettes-vaping-juuls/.

28. Sanders-Jackson, A., Schleicher, N., Fortmann, S., \& Henriksen, L. (2019, June 20). Effect of warning statements in e-cigarette advertisements: an experiment with young adults in the United States. Retrieved from http://csulb.idm.oclc.org/login?url= https://search.ebsc ohost.com/login .aspx?direct=tru $e \& d b=r z h \& A N=110900824 \&$ site $=$ ehost-live .

29. Schaeffer, K. (2019, September 26). Before recent outbreak, vaping was on the rise in U.S., especially among young people. Retrieved from https://www. pewresearch.org/fact-tank/2019/09/26/vapingsurvey-data-roundup/.

30. Standford. (2019). Tobacco laws: e-cigarettes. Retrieved from https://med.stanford.edu/content/ dam/sm/tobaccopreventiontool kit/documents/scho ol-policy/Tobacco\%20Laws.pdf

31. Tobacco Free Kids. (2019, December 4). U.S. state and local issues: raising the tobacco age to 21 . Retrieved from https://www.tobaccofreekids.org/ what-we-do/us/sale-age-21

32. Truth Initiative. (2019, November 11). E-cigarettes: Facts, stats and regulations. Retrieved from https:// truthinitiative.org/research-resources/emergingtobacco-products/e-cigarettes-facts-stats-andregulations.

33. Wang T. W., Gentzke A, \& Sharapova S, et al. (2018) Tobacco use among middle and high school students - United States, 2011-2017. MMWR Morbidity and Mortality Weekly Report, 2018, 67(22), 629-633.

34. Wu, J. (2019, October 1). E-cigarette sales slowing, led by juul, amid negative headlines. Retrieved from https://www.cnbc.com/2019/10/01/e-cigarette-sales -slowing-led-by-juul-amid-negative-headlines.html. 